\title{
Correction to: A Cost Analysis of Haemodialysis and Peritoneal Dialysis for the Management of End-Stage Renal Failure At an Academic Hospital in Pretoria, South Africa
}

\author{
Letlhogonolo Makhele $^{1} \cdot$ Moliehi Matlala ${ }^{1} \cdot$ Mncengeli Sibanda $^{1} \cdot$ Antony P. Martin $^{2,3} \cdot$ Brian Godman $^{1,2,4,5}$ (D)
}

Published online: 26 June 2019

(c) The Author(s) 2019

\section{Correction to: PharmacoEconomics - Open https://doi.org/10.1007/s41669-019-0124-5}

Multiple errors have been identified in the article including in the main findings.

For example, two sentences in the abstract, Results, which read:

"Variable costs (HD: US\$172, 359.15; PD: US\$20, 488.79) were found to be the biggest cost drivers for both treatment modalities. The annual cost of HD per patient (US\$205, 681.40) was higher than PD (US\$25, 282.00 per patient), even though the difference was not statistically significant $(p=0.175)$ ".

Should have read:

"Fixed costs were the principal cost driver for HD $(\$ 16,231.45)$ while variable costs were the principal cost driver for PD (US\$20,488.79). The annual cost of HD per patient (US\$31,993.12) was higher than PD (US\$25,282.00 per patient), even though the difference was not statistically significant $(p=0.816)$ ".

The original article can be found online at https://doi.org/10.1007/ s41669-019-0124-5.

Brian Godman

Brian.Godman@strath.ac.uk; Brian.Godman@ki.se

Letlhogonolo Makhele

makhele.nolo@gmail.com

Moliehi Matlala

moliehi.matlala@smu.ac.za

Mncengeli Sibanda

mncengelis@gmail.com

Antony P. Martin

a.p.martin@liverpool.ac.uk;

antony.martin@hcdeconomics.com
Errors were also identified in the following locations:

- Section "3 Results"

- Section "4 Discussion"

- Table 1

- Table 3

- Figure 2

- Table 6

- Section "5 Conclusion"

The article has now been updated to correct the errors.

Open Access This article is distributed under the terms of the Creative Commons Attribution-NonCommercial 4.0 International License (http://creativecommons.org/licenses/by-nc/4.0/), which permits any noncommercial use, distribution, and reproduction in any medium, provided you give appropriate credit to the original author(s) and the source, provide a link to the Creative Commons license, and indicate if changes were made.
1 Department of Public Health and Pharmacy Management, School of Pharmacy, Sefako Makgatho Health Sciences University, Pretoria, South Africa

2 Health Economics Centre, University of Liverpool Management School, Chatham Street, Liverpool, UK

3 HCD Economics, The Innovation Centre, Daresbury WA4 4FS, UK

4 Strathclyde Institute of Pharmacy and Biomedical Sciences, University of Strathclyde, Glasgow G4 ORE, UK

5 Division of Clinical Pharmacology, Karolinska Institute, Karolinska University Hospital Huddinge, 14186 Stockholm, Sweden 